\title{
EXUDATIVE AGE-RELATED MACULAR DEGENERATION IN PATIENTS WITH DIABETIC RETINOPATHY AND ITS RELATION TO RETINAL LASER PHOTOCOAGULATION
}

\author{
ROGER ZYLBERMANN ${ }^{1}$, DAVID LANDAU ${ }^{1}$, YAACOV ROZENMAN ${ }^{1}$, \\ SIMON ABRAHAMI ${ }^{2}$ and AYALA POLLACK ${ }^{2}$ \\ Jerusalem and Rehovot, Israel
}

\begin{abstract}
SUMMARY
Purpose: To study the relationship between exudative age-related macular degeneration and diabetic retinopathy and assess the influence of retinal laser photocoagulation for diabetic retinopathy on the occurrence of exudative age-related macular degeneration.

Methods: Two groups, one of diabetic retinopathy patients treated with laser and the other of non-lasertreated diabetic retinopathy patients, were studied by means of fundoscopy and fluorescein angiography for the presence of exudative age-related macular degeneration.

Results: Exudative age-related macular degeneration was not observed in 431 patients treated with laser photocoagulation, and was diagnosed in $3.3 \%$ of 151 non-laser-treated patients.

Conclusion: Patients treated by laser photocoagulation for diabetic retinopathy are less prone to develop the exudative form of age-related macular degeneration.
\end{abstract}

Exudative age-related macular degeneration (EAMD) and diabetic retinopathy (DR) are the most frequent sight-threatening diseases of the elderly in the Western world. During the last decades, several authors ${ }^{1-11}$ have examined the epidemiological aspect of EAMD, but the relationship between EAMD and DR was poorly documented. The aim of this study was to gain more information about the occurrence of EAMD in patients with DR and to evaluate the effect of laser photocoagulation for DR on the development of EAMD.

From: ${ }^{1}$ Shaare Zedek Medical Center, Jerusalem; ${ }^{2}$ Kaplan Hospital, Rehovot, Israel.

Correspondence to: Dr Roger Zylbermann, The Ophthalmology Department, Shaare Zedek Medical Center, P.O.B. 3235 Jerusalem 91031, Israel. Tel: 972-2-6555111. Fax: 972-2-6513946.

\section{PATIENTS AND METHODS}

From January 1989 to December 1993 all patients, 55 years or older, with DR who were sent for fundus fluorescein angiography to evaluate $\mathrm{DR}$ grade and the need for retinal laser photocoagulation were recruited from the outpatient clinics of the Shaare Zedek Medical Center in Jerusalem and of the Kaplan Hospital in Rehovot. For each patient, a standardised protocol was completed, giving detailed demographic and clinical information including duration of diabetes mellitus, presence of other systemic diseases and medication used. Eye examination included best corrected visual acuity, refraction, applanation tonometry, biomicroscopy, indirect ophthalmoscopy and Goldmann three-mirror examination, colour fundus photography and fluorescein angiography (five $60^{\circ}$ fields). In each centre only one retinal specialist (R.Z., A.P.) evaluated the photographs. Patients with associated macular pathology secondary to other retinal diseases such as retinal branch vein occlusion, high myopia and other were excluded.

The patients were classified into two main groups: laser-treated DR patients and non-laser-treated DR patients. Laser treatment was done according to the guidelines of the Diabetic Retinopathy Study $(\mathrm{DRS})^{12}$ and the recommendations of the Early Treatment Diabetic Retinopathy Study (ETDRS). ${ }^{13}$ Each main group was subdivided into non-proliferative diabetic retinopathy (NPDR) and proliferative diabetic retinopathy (PDR) subgroups. Patients were graded according to the eye with the worse DR at the last visit or at the time of discovery of the EAMD. Concurrently, we searched for the presence of abnormalities related to age-related macular degeneration (AMD): drusen, retinal pigment epithelial

Eye (1997) 11, 872-875 C 1997 Royal College of Ophthalmologists 
Table I. Retinal status

\begin{tabular}{lrrrr}
\hline & \multicolumn{4}{c}{ Age (years) } \\
\cline { 2 - 3 } & $55-64$ & $65-74$ & $\geqslant 75$ & $\begin{array}{c}\text { All } \\
\text { patients }\end{array}$ \\
\hline Laser-treated patients & & & & \\
All patients & 166 & 171 & 94 & 431 \\
NPDR & 116 & 126 & 74 & 316 \\
PDR & 50 & 45 & 20 & 115 \\
Non-laser-treated patients & & & \\
All patients & 57 & 59 & 35 & 151 \\
NPDR & 52 & 58 & 35 & 145 \\
PDR & 5 & 1 & 0 & 6 \\
\hline
\end{tabular}

NPDR, non-proliferative diabetic retinopathy; PDR, proliferative diabetic retinopathy.

(RPE) changes in the macula, geographic atrophy and EAMD. EAMD was defined by one or more of the following: RPE detachment, sensory retinal detachment, presence of subretinal neovascular membrane on the fluorescein angiogram.

\section{RESULTS}

Five hundred and eighty-two (582) patients with DR were included (299 men and 283 women). Twenty-six per cent of the diabetic patients (154 patients) were insulin treated (of these, 11 patients had early onset diabetes mellitus) and the other three-quarters of the patients (428 patients) had non-insulin-dependent diabetes mellitus. Forty per cent of patients had systemic hypertension (more than $145 \mathrm{mmHg}$ systolic and/or more than $90 \mathrm{mmHg}$ diastolic).

With aging, frequencies of emmetropia and myopia decreased, while hypermetropia increased from $17 \%$ to $37.2 \%$. Glaucoma was noted in $9.42 \%$ of patients in the youngest age group and in $12 \%$ in the oldest. Four hundred and thirty-one patients (431) were treated with laser photocoagulation for DR complications; 151 patients were not treated by laser (Table I). Retinal pathology related to AMD was observed in 59 patients (Table II); among these, soft drusen and RPE changes were noted in 12 patients in the non-laser-treated group (8.6\%) and in 13 patients in the laser-treated group (2.8\%). Five patients $(3.3 \%)$ of the non-laser-treated group developed EAMD but none in the laser-treated group (chi-squared $=14.39$, one degree of freedom, $p<0.0005)$. Two patients had bilateral EAMD. In 6 eyes a well-defined choroidal neovascular membrane was present. In one eye there was a pigment epithelium detachment (PED). Data on 5 patients in whom we found EAMD are given in Table III.

\section{DISCUSSION}

In our study the prevalence of EAMD in patients with DR was only $0.86 \%$. This prevalence is lower than the prevalence of EAMD in the general population as published in the Framingham Eye Study $(1.5 \%),{ }^{14}$ in Vinding's study in Copenhagen $(2.1 \%){ }^{15}$ and in the Beaver Dam Study $(1.2 \%){ }^{16}$ There is controversy in the literature concerning the prevalence of EAMD among DR patients. Gass, ${ }^{1}$ when searching for the aetiology of AMD, found only one patient with DR in a group of 150 patients with EAMD. In the Framingham Eye Study ${ }^{14}$ this association was present in one eye among 5253 examined eyes. A relative rarity of EAMD in DR patients was also remarked by Benson et al. ${ }^{17}$ However, Klein et al. ${ }^{16}$ in the Beaver Dam study observed that in people 65 years or older, the prevalence of EAMD was $2.3 \%$ in 1704 nondiabetics, $5 \%$ in 142 diabetics without DR and $3.4 \%$ in 83 diabetic patients with DR. Klein et al. did not separate the laser-treated DR patients from the non-laser-treated in their 83 DR patients. They concluded that there was no statistically significant relationship between EAMD and DR. In our study the prevalence of EAMD in all DR patients was as low as $0.86 \%$. However, when we distinguished between laser-treated and non-laser-treated DR patients we found a prevalence of $3.3 \%$ among 151 non-laser-treated DR patients. Our results among the non-laser-treated DR patients are similar to those published by Klein et al. among 88 patients with DR. In contrast none of our 431 laser-treated DR patients developed EAMD. Drusen and RPE alterations were less frequent in the laser-treated group than in the non-laser-treated group.

Understanding the reasons that govern the low prevalence of AMD in DR is difficult. The early signs of AMD are drusen, which are debris observed in Bruch's membrane. They are supposed to result from the metabolic activity of the external retinal layer and $\mathrm{RPE},{ }^{18,19}$ or from the choroidal circulation, ${ }^{20,21}$ or both. DR is mainly a microangiopathy of the

Table II. Characteristics of age-related macular degeneration in diabetic retinopathy patients

\begin{tabular}{|c|c|c|c|c|c|c|c|c|}
\hline \multirow[b]{2}{*}{$\begin{array}{l}\text { AMD } \\
\text { characteristic }\end{array}$} & \multicolumn{2}{|c|}{ Age $55-64(n=223)$} & \multicolumn{2}{|c|}{ Age $65-74(n=230)$} & \multicolumn{2}{|c|}{ Age $\geqslant 75(n=139)$} & \multicolumn{2}{|c|}{ All patients $(n=582)$} \\
\hline & $\begin{array}{c}\text { NLT } \\
(n=57)\end{array}$ & $\begin{array}{c}\mathrm{LT} \\
(n=166)\end{array}$ & $\begin{array}{c}\text { NLT } \\
(n=59)\end{array}$ & $\begin{array}{c}\mathrm{LT} \\
(n=171)\end{array}$ & $\begin{array}{c}\text { NLT } \\
(n=35)\end{array}$ & $\begin{array}{c}\mathrm{LT} \\
(n=94)\end{array}$ & $\begin{array}{c}\text { NLT } \\
(n=151)\end{array}$ & $\begin{array}{c}\mathrm{LT} \\
(n=431)\end{array}$ \\
\hline Hard drusen & 3 & 1 & 6 & 3 & 0 & 2 & 9 & 6 \\
\hline Soft drusen & 1 & 1 & 2 & 1 & 0 & 0 & 3 & 2 \\
\hline RPE changes & 3 & 4 & 2 & 5 & 4 & 2 & 9 & 11 \\
\hline EAMD & 1 & 0 & 2 & 0 & 2 & 0 & 5 & 0 \\
\hline Geographic atrophy & 1 & 0 & 3 & 0 & 0 & 0 & 4 & 0 \\
\hline
\end{tabular}

NLT, non-laser-treated group; LT, laser-treated group; RPE, retinal pigment epithelium; EAMD, exudative age-related macular degeneration. 
Table III. Characteristics of patients with exudative age-related macular degeneration

\begin{tabular}{|c|c|c|c|c|c|}
\hline \multirow[b]{2}{*}{ Characteristics } & \multicolumn{5}{|c|}{ Patient no. } \\
\hline & 1 & 2 & 3 & 4 & 5 \\
\hline Age at diagnosis of EAMD (years) & 55 & 64 & 71 & 75 & 82 \\
\hline Sex & $\mathrm{F}$ & M & $\mathrm{M}$ & $\mathrm{F}$ & $\mathrm{M}$ \\
\hline Type of diabetes & NIDDM & NIDDM & NIDDM & NIDDM & NIDDM \\
\hline Duration of diabetes (years) at diagnosis of EAMD & 19 & 26 & 19 & 20 & 9 \\
\hline Type of retinopathy at diagnosis of EAMD & NPDR & NPDR & NPDR & NPDR & NPDR \\
\hline Laser treatment before diagnosis of EAMD & No & No & No & No & No \\
\hline
\end{tabular}

EAMD, exudative age-related macular degeneration; NIDDM, non-insulin-dependent diabetes mellitus; NPDR, non-proliferative diabetic retinopathy.

retinal and choroidal vasculature. In the retina, there is a progressive thickening of the basement membrane of the retinal capillary wall, the sequelae of which are retinal oedema and ischaemia. The diabetic choroidal vasculature is characterised by narrowing of the capillary lumen, with thickening of the basement membrane of the choriocapillary walls, loss of pericytes and proliferation of endothelial cells. At an advanced stage, capillary drop-out and focal scarring occur. 22,23 AMD and DR involve the sensory retina, RPE, Bruch's membrane and choroid. A possible explanation of the relation between AMD and DR is that the alteration of the metabolic activity of the retina, RPE and vascular choroidal compromise over the years may diminish the production of debris that accumulates in Bruch's membrane and forms drusen. Another possible explanation is that the advanced alteration in the choroidal vascular bed and the modified structure of Bruch's membrane in severe DR may interfere with the deposition of drusen resulting in arrest of the progress to EAMD. It seems that the more advanced the DR, the more pronounced is the prevention of AMD. DR, by definition, was more advanced in the laser-treated group than in the non-laser-treated group, and this may explain why drusen and RPE alterations were less frequent in the laser-treated group $(2.8 \%)$ than in the non-laser-treated group $(8.6 \%)$.

The complete absence of EAMD among the lasertreated DR group may also be explained by the effect of laser photocoagulation on the retina. Retinal laser photocoagulation has been shown to be associated with the disappearance of drusen., ${ }^{1,24-27}$ Duvall and $\mathrm{Tso}^{24}$ have shown experimentally that exposure of drusen to a mild laser burn was followed by dissolution of drusen. They suggested that two kinds of phagocytic cells induced by a local inflammatory reaction removed the extracellular material accumulated in Bruch's membrane. Laser photocoagulation in DR may induce this local inflammatory reaction. Through this mechanism, the evolution of AMD and development of choroidal neovascularisation may be partially blocked. Further studies are needed to better understand the mechanisms involved. Our study suggests that patients with DR who were treated by retinal laser photocoagulation are less prone to develop the exudative form of AMD and this may support indirect evidence of the beneficial effect of laser photocoagulation in halting progression of EAMD.

Key words: Diabetic retinopathy, Exudative age-related macular degeneration, Laser photocoagulation.

\section{REFERENCES}

1. Gass JDM. Drusen and disciform macular detachment and degeneration. Arch Ophthalmol 1973;90:206-17.

2. Kahn HA, Leibowitz HM, Ganley JP, Kini MM, Colton T, Nickerson RS, Dawber TR. The Framingham eye study. II. Association of ophthalmic pathology with single variables previously measured in the Framingham heart study. Am J Epidemiol 1977;106: 33-41.

3. Maltzman BA, Mulvihill MN, Greenbaum A. Senile macular degeneration and risk factors: a case-control study. Ann Ophthalmol 1979;11:1197-201.

4. Delaney WV, Oates RP. Senile macular degeneration: a preliminary study. Ann Ophthalmol 1982;14:21-4.

5. Hyman LG, Lilienfeld AM, Ferris FL III, Fine SL. Senile macular degeneration: a case-control study. Am J Epidemiol 1983;118:213-27.

6. Vidaurri JS, Pe'er J, Halfon S, Halperin G, Zauberman $\mathrm{H}$. Association between drusen and some of the risk factors for coronary artery disease. Ophthalmologica 1984;188:243-7.

7. Gibson M, Shaw DE, Rosenthal AR. Senile cataract and senile macular degeneration: an investigation into possible risk factors. Trans Ophthalmol Soc UK 1986;105:463-8.

8. Blumenkrantz MS, Russel SR, Robey MG, KottBlumenkrantz R, Penneys N. Risk factors in agerelated maculopathy complicated by choroidal neovascularisation. Ophthalmology 1986;96:552-8.

9. Bressler NM, Bressler SB, Fine SL. Age-related macular degeneration. Surv Ophthalmol 1988;32: 375-413.

10. Vinding T. Age-related macular degeneration: macular changes, prevalence and sex ratio. Acta Ophthalmol (Copenh) 1989;67:609-16.

11. Klein R, Klein BEK, Moss SE. Diabetes, hyperglycemia, and age-related maculopathy: the Beaver Dam eye study. Ophthalmology 1992;99:1527-34.

12. The Diabetic Retinopathy Study Research Group. Photocoagulation treatment of proliferative diabetic retinopathy: clinical application of diabetic retinopathy study (DRS) findings. DRS report no 8. Ophthalmology 1981;88:583-91.

13. Early Treatment Diabetic Retinopathy Study Research Group. Photocoagulation for diabetic macular edema. Arch Ophthalmol 1985;103:1796-802. 
14. Leibowitz HM, et al. The Framingham eye study monograph. Surv Ophthalmol 1980;(Suppl)24:335-610.

15 . Vinding T. Occurrence of drusen, pigmentary changes and exudative changes in the macula with reference to age-related macular degeneration. Acta Ophthalmol (Copenh) 1990:68:410-4.

16. Klein R, Klein BEK, Linton KLP. Prevalence of agerelated maculopathy: the Beaver Dam eye study. Ophthalmology 1992;99:933-43.

17. Benson WE, Brown GC, Tasman W. Diabetes and its ocular complications. Philadelphia: WB Saunders, 1988:71.

18. Farkas TG, Krill AE, Sylvester VM, et al. Familial and secondary drusen. Trans Am Acad Ophthalmol Otolaryngol 1971;75:333-43.

19. Hogan MJ. Role of retinal pigment epithelium in macular drusen. Trans Am Acad Ophthalmol Otolaryngol 1972;76:64-80.

20. Friedman E, Smith TR, Kuwabara T. Senile choroidal vascular pattern and drusen. Arch Ophthalmol 1963; 69:220-30.
21. Gass JDM. Pathogenesis of disciform detachment of the neuroepithelium. III. Senile disciform macular degeneration. Am J Ophthalmol 1967;63:617-45.

22. Hidayat AA, Fine BS. Diabetic choroidopathy: light and electron microscopic observation of seven cases. Ophthalmology 1985;92:512-22.

23. Fryczkowsky AW, Sato SE, Hodes BL. Changes in the diabetic choroidal vasculature: scanning electron microscopy findings. Ann Ophthalmol 1988;20: 299-305.

24. Duvall J, Tso MOM. Cellular mechanisms of resolution of drusen after laser coagulation: an experimental study. Arch Ophthalmol 1985;103:694-703.

25. Wetzig PC. Treatment of drusen-related aging macular degeneration by photocoagulation. Trans Am Ophthalmol Soc 1988;86:276-90.

26. Sigelman J. Foveal drusen resorption a year after perifoveal laser photocoagulation. Ophthalmology 1991;98:1379-83.

27. Figueroa MS, Regueras A, Bertrand J. Laser photocoagulation to treat macular soft drusen in age-related macular degeneration. Retina 1994;14:391-6. 